\title{
Laterality of voluntary motor tasks: Are basketing, targeting, and peg-moving performance asymmetric?
}

\author{
Yalçin Yetkin ${ }^{1 *}$ and Koksal Erman ${ }^{2}$ \\ ${ }^{1}$ Department of Physiology, Medical Faculty, Yüzüncü Yil University, 65 200, Van, Turkey. \\ ${ }^{2}$ Department of Biology, Science Faculty, Atatürk University, 25 240, Erzurum, Turkey. \\ Accepted 27 January, 2012
}

\begin{abstract}
The principal objective of this work is to investigate the relationship between lateral functions of the brain and morphology of the hands, eyes and feet. The study was carried out with 233 volunteers within the age range of 18 to 27 years. Out of the total number of participants, $208(94 \%)$ of them were righthanded and the remaining $13(6 \%)$ were left-handed. The participants were divided into two groups and assessed by twenty items. First ten (Q1) and second ten (Q2) items were taken from Edinburg Handedness Inventory (EHI) and the Yetkin Laterality Questionnaire (YLQ). The degree of hand preference was determined by Geshwind scores (GSs). Q1 was used to assess only hand preference, while Q2 was used for laterality of the one side of the body from eye to foot. Statistically, nonsignificant ( $p>0.05)$ difference $(3 \%)$ was observed between the Q1 $(63 \%)$ and Q2 $(60 \%)$. Breadths and lengths of the hands were measured across 2 to 5 metacarpal region, from peripheral line on the wrist to middle fingertip. While the difference between the breadths of right and left hand was significant $(p<0.05)$, the difference between the lengths of hand was non-significant $(p>0.05)$. The breadths and lengths of the feet were also measured in the same way. Subjects performed three different voluntary motor activities, such as basketing (throwing basketball: BT), aiming at (targeting: TT) and peg moving tasks (PMT) with their right and left hands in turn to perform the tasks, respectively. In the BT and TT tasks, the difference between the right and left hand performance was non-significant $(p>0.05)$, though, the difference was significant $(p<0.05)$ for PMT. The findings suggest that both the proximity of the hand preferences and the difference of the hand sizes could be the results of the hemispheric dominance in the brain. In this study, it was found that there was a significant difference for left- versus right- hand breadths and left and right-hand motor performances which is shown to be both morphological and functional in asymmetry.
\end{abstract}

Key words: Laterality, hand preference, basketing, targeting, peg-moving, motor performances, brain asymmetry, human.

\section{INTRODUCTION}

Most of the studies on the functional asymmetries are recent, although the first observation of the brain asymmetry is that of Broca (1861) (Yetkin, 2001). Since the first evidence of the functional asymmetry was first implied by Broca, the left hemispheres are important for fine control of motor skills in distal extremities (Mohr, 1976; Purves et al., 2001). The pioneering works of Broca (1861) and Wernicke (1874), and later Geshwind (1965) and Sperry (1974) clearly established the

\footnotetext{
*Corresponding author. E-mail: yyetkin@yyu.edu.tr
}

differences in hemispheric functions (Hellige, 1990). Handedness is also first and fore most an example of the advantage of having a specialized function on one side of the brain (Geshwind, 1967; Bakan, 1975; Wilson, 1998). Hand preferences and brain asymmetry are commonly assumed to be unique in both human (Corballis, 2009) and non-human species (Glick and Shapiro, 1985). Every morning, even before individuals were out of bed, their hands come to life, goading their weak and helpless body into the day (Wilson, 1998).

In the hemispheric dominance, the left cerebral hemisphere is closely related to complex motor control; some non-language motor skills are tightly associated 
with the brain functions. Brain organization for such functions is rather different in left- and right-handed individuals, as well as between men and women (Kimura, 1993). Kimura's (1996) latest studies have also shown that there are important differences in the way the brain is organized between one person and another. These differences may underlie some of our unique talents. In the book "Hand und Wort", written by André LeroiGourhan (1988), bilateral symmetry and the relationship between hand and external and internal-world has been narrated successfully. Some motor asymmetry methods have also been described by Kimura (2011). One of the most remarkable features of complex functions is the ability to use the hands with elaborate skill (Vogan and Tabin, 1999). This emerges clearly when using hands in daily activities. Moreover, the sizes of the two hands are most probably different. This difference may come from either laterality or from using one hand more often than the other. People can actually compare each of their hands to verify this difference. The hand of the human being also has a long history since the beginning of the human civilization on its social interaction and attention (Young, 1983).

Both biologically and physiologically, the left and right hemispheres undertake different functions (Geshwind and Galaburda, 1984, 1987). Thus, asymmetry arises functionally and anatomically. In biology, symmetry is a definition that denotes the arrangement of the body parts of a living being in a particular order, according to the line dividing the body in two similar parts, in respect to dimension, shape and position on both sides. In addition, symmetry is an important feature of the body in biological systems maintaining a physical quantity such as the protection of energy and balance of the body (Yetkin, 1993). The left hemisphere seems to be heavier and denser than the right hemisphere of the brain (Yetkin, 2002a). The left hemisphere is dominant with respect to the control of the right side (Rothwell, 1994) of the body. In humans, approximately 90 to $95 \%$ of the general population is shown to be right-handed, that is, they prefer their right hand for intricate, complex acts, and are more skillful with it (Annet, 1985, 1996; Tan, 1993a; Yetkin, 1993; Adams et al., 1997).

However, the right hemisphere seems to be more voluminous than the left hemisphere. The dominancy of right hemisphere is about 5 to 10\% (Geschwind, 1971; Tan and Kutlu, 1992; Yetkin, 2002b). In right-handed people, left and right hemispheric dominance are 96 and $4 \%$, respectively (Wada et al., 1975; Kupfermann, 1999). Having individuals answer a series of questions about preferred manual behaviors such as "which hand do you use to write, to throw a ball, to brush your teeth?" were used to assess handedness. In the same way, laterality of the feet and eyes can be assessed with questions such as "which foot do you use to kick a ball?" or "which foot do you use to play hopscotch?" and "which eye do you use to look in a microscope?" Each answer is given a value, which then provides a quantitative measure of the inclination toward right- or left-handedness (Coren, 1992; Davidson and Hugdal, 1995). For the relationship among human hand preferences (Annet, 1972; Tan, 1988, 1993b), hand sizes (Yetkin, 1995, 2002a) and voluntary motor skills (Tan, 1992; Yetkin, 2002b), a few modeling studies addressing these questions are available. Anthropologists have estimated the incidence of handedness in ancient cultures (Tattersall, 1995) by examining artifacts. Based on this evidence, humans have been mostly right-handed as far back as can be ascertained. Handedness is not peculiar only to humans; many studies have demonstrated paw preference in animals, at least in some ways, similar to human handedness (Purves et al., 2004). The present study focused on the effect of using the dominant hand during daily activities on its anatomical sizes and functional preferences (Long, 1981). Size differences of hands and feet as related to the laterality are in part, the results of changes of the activity of preferable hand and foot in daily life. The genetic information is increasingly considered in functional rather than structural terms, but time to time, the structural phenomena remain predominant in humans (Reeves, 2000). The genetic program which directs their development is also proving to be complex. Trying to understand how it works is keeping researchers busy (Cohn, 2002). Several mechanisms could be responsible for the differences evident of hand and foot sizes, as well as their preferences (Adams et al., 1997; Purves at al., 2001).

For the lateral function, it has been suggested that it is important to motor, mental, emotional, perceptual and cognitive functions. The physiology of the human hand pushes currently on emotional interests in the research of motor functions. Although the fine manual motor skills are complex, researches provide important improvement in the understanding of the interested mechanisms (Wiesendanger and Nirkko, 2001). In this paper, the necessity of the bimanual coordination and adaptation of the hand in observation of the subjects were investigated. For this purpose, this study aims to assess the breadth and length of the hand and foot in relation to their lateral functions with a metric dimension in both the right and left hands and feet of men and women subjects. Inquiries were also made for learning, to confirm if there are differences between the dimensions of left and right hands and feet sizes as morphologic asymmetry. On the other hand, the velocity of the hand using PMT was studied by inserting nails into a hole on a table having a hundred holes. Details of this are discussed subsequently.

\section{METHODS}

\section{Subjects}

The present study was carried out with young volunteer students $(\mathrm{N}=233)$ whose age range is from 19 to 27 years (mean $22 \pm 2$ years). The participants were the students in Biology and Nursing Sciences of Atatürk University in Erzurum, Turkey. None of them 
had a history of neurological and psychological disorders. They were also in healthy condition and neither of them had tissue damage nor defect on their hands and feet. They were divided into two groups: the first group included 22 subjects and the second group included 211 subjects (Table 1 ).

\section{Assessing of hand preferences and laterality degrees}

Hand preference and laterality of the participants was assessed by means of twenty item questionnaire with two groups (Yetkin, 2001). The first group with ten items (Q1=G1) was taken from Edinburg Handedness Inventory (EHI; Oldfield, 1971) and translated for the Turkish population by Tan (1988) and Yetkin (1993). Respondents were asked to indicate which hand they used in "writing", "drawing", "throwing", or "using scissors", "toothbrush", "knife", "spoon", "broom (upper hand)" "striking a match" and "removing a lid". The second group of Handedness Inventory with ten items (Q2=G2) was developed by Yetkin (YLQ/I: 1993, 1995, 2001) to assess the whole lateralization degree of one side of the body. Respondents were also asked to indicate which hand, foot and eye they used in "looking through a microscope", "passing a thread through a needle", "kicking a ball", "aiming at (with hand, finger and eye)", "shaking hand and saluting", "sewing", "holding a saw", "throwing a hammer", "carrying a suitcase", and "playing hop-scotch". These two questionnaires have been composed by Yetkin (1993) in his studies. Thus, a new questionnaire with twenty questions has been created to assess the whole laterality. For every two groups, the columns of the questionnaires were scored as " +10 (always right hand: AR-H)", " +5 (usually right hand: UR_H)", "zero point (either hand/or side: EH-S)", "-5 (usually left hand: UL-H)", and "-10 (always left hand: AL-H)". The Composed Handedness Inventory (CHI) was administered to a sample of 233 students, comprising 90 (40.4\%) men and 143 (59.6\%) women in different disciplines of the university. Before given a task, all subjects took composed Handedness Inventory in Turkish translation by Tan (1988) and Yetkin $(1993,2003)$. The first part of the questionnaire (Q1) included ten items taken from EHI, and the second part (Q2) included ten items taken from YLQ. A different composed questionnaire was used for the assessment of the laterality (Steenhuis and Bryden, 1989). Respondents were asked to indicate which hand they would use in daily activities. Subjects were also tested for the actions related to the questions. Before the voluntary tasks, the laterality degrees were assessed by Geshwind scores (GSs), and and then the planned voluntary actions were shown to the subjects to familiarize them with the actions before they perform them. While the first group of actions (Q1) was directly related to the hand preferences, the second group of actions (Q2) was related to the laterality of the other parts of the body, including eye, hand and foot preferences. After the assessment of the preferences, GSs were used for laterality degrees.

\section{Left (LH) - right hand (RH) and left (LF) - right foot (RF) sizes}

The anthropometric measurements of the dimensions of hands and feet were made by using a sensible electronic compass $( \pm 0.01$ $\mathrm{mm})$. The subjects were seated on a comfortable chair similar to an armchair for watching TV. The right and left arms were set at the upper side of the supporting winds of the armchair as to wrist of the hands. Thus, their feet and hands were free and without suppression. The muscles of the hands and feet were kept on their special position and tension. The palm of the hand was faced in a similar manner to the flat surface and the foot was in the normal upright position. Then, the breath and lengths of the right $(\mathrm{RH})$ and left hands (LH), and right (RF) and left foot (LF) were measured by sliding compass.

\section{The breadth of the hands}

The hand characteristics of palm breadth and distal point of the middle finger were measured from 233 subjects that performed activities like throwing basketball, targeting and peg-moving task. To measure the breadth, the hands were kept free on the position as parallel to the ground with the fingers closed side by side except the thumb being $45^{\circ}$ apart from the others. The inter-metacarpal line from $2^{\text {nd }}$ to $5^{\text {th }}$ metacarpus was measured as breadth of the hand (Figure 1).

\section{The measurement of the length of the hands}

The length of the left and right hands were measured while the palm of the hand was kept on the position which could be seen. The length of the hand was measured from transfer carpal ligament $(\mathrm{Tcl})$, which lies between interstyloid on the surface of the wrist, to the middle fingertip. The line between antero-brachial fascia (Anbf) and Tcl can be seen on the skin surface of the wrists (Figure 2).

\section{The measurement of the breath of the feet}

The breath of the feet was measured while the subjects were on the sitting position. The distance between the first and fifth metatarsals was taken as foot breath (Figure 3a).

\section{The length of the feet}

In the same way, the length between the skin surface of the calcanei and the fingertip of the foot's thumb was taken as foot length (Figure 3b).

\section{Motor tasks: Basketball, targeting and peg-moving (inserting a nail in a hole)}

The functional apparatus that was developed by Yetkin (1995) for some voluntary tasks was used in the present study. The features of the apparatus have been described and calculated in previous studies (Yetkin, 1995, 2002b).

\section{Basketing (throwing basketball) task (BT)}

The subjects performed basketball actions at the basket set (Yetkin, 1995). The action of basketball was repeated a hundred times. They threw a special rubber ball of $7 \mathrm{~cm}$ diameter by using their left and/or right hands from a distance of $3 \mathrm{~m}$ into a basket that is 25 $\mathrm{cm}$ in diameter and placed $160 \mathrm{~cm}$ above ground on a board of 100 $\times 100 \mathrm{~cm}$ in dimensions. At the end of these trials, the basketing performances of the subjects were recorded in percentage (Table $1)$.

\section{Targeting /or aiming at (TT task)}

The set of targeting task was also developed by Yetkin (1995). The participants walked from a $3 \mathrm{~m}$ distance toward a board to touch target point placed on the board that was $75 \times 75 \mathrm{~cm}$ in dimensions. They were asked to use their index fingers to touch the target point that was $157.5 \mathrm{~cm}$ high from the ground, perform targeting task hundred times with their right and left hands, respectively, and the targeting performance was determined in percentage (Table 1).

\section{Peg-moving task (PMT)/ or Sarah-peg works}

This activity is related to inserting pegs (nails) in holes. The set contained 100 holes $(20 \times 5$ holes $)$ on a board. The subjects were required to insert 100 pegs into the holes. The time spent for this 


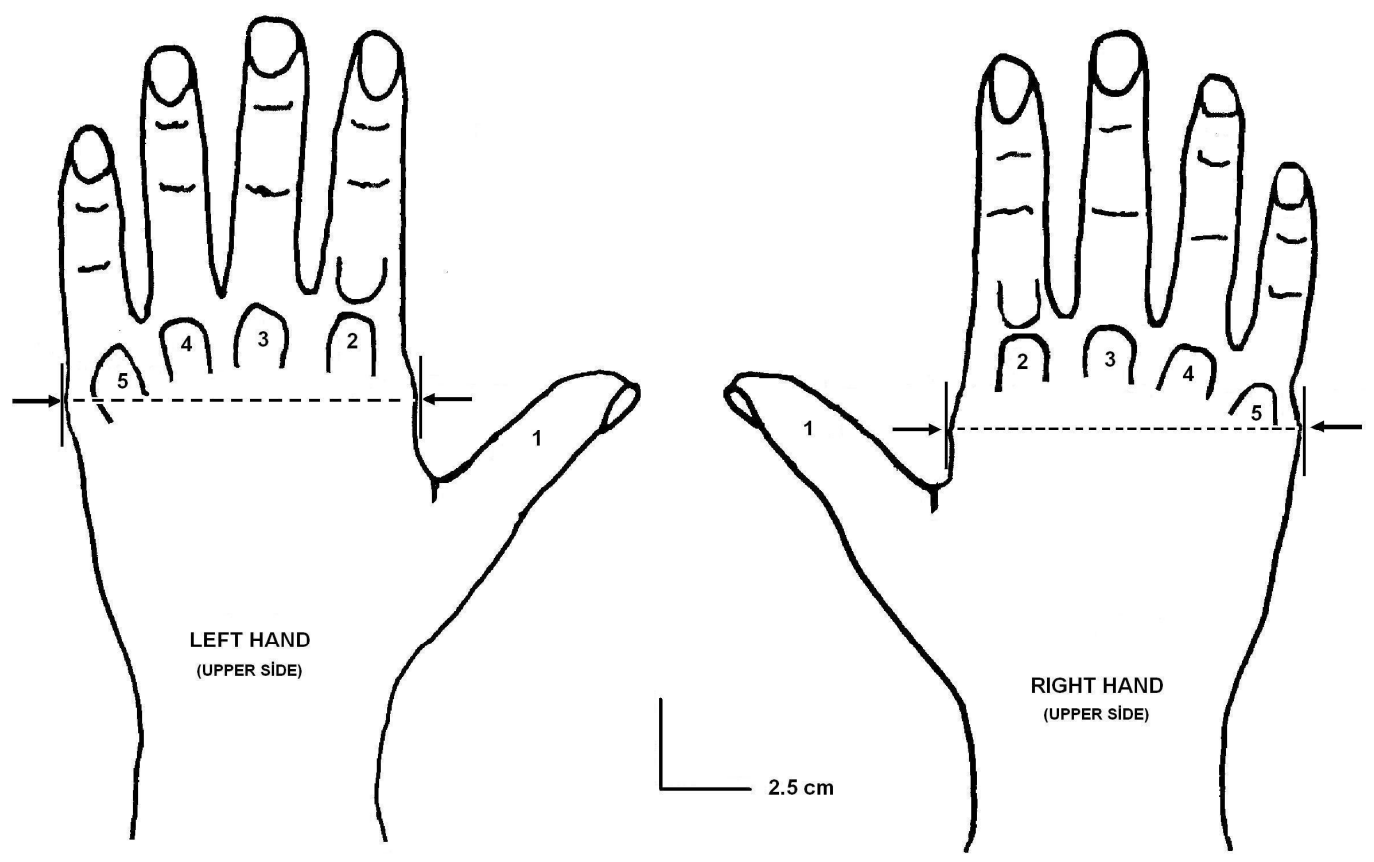

Figure 1. The reference points for measurement of the breadth of the left- and right hands. The longest line was measured on the palm from the $2^{\text {nd }}$ to the $5^{\text {th }}$ metacarpi as the breath of the hands. The arrows indicate the widest points of the right and left hands on the palm.
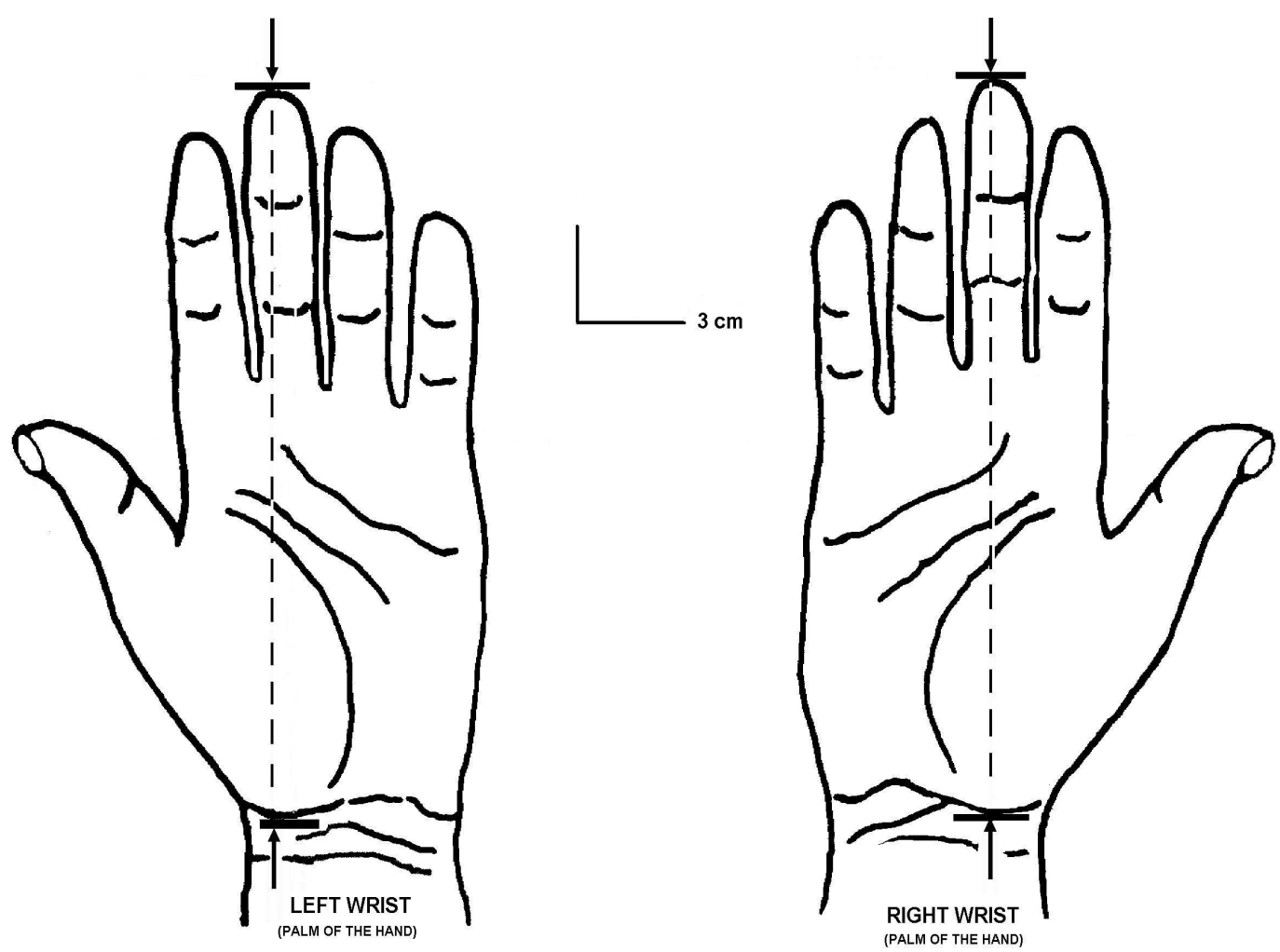

Figure 2. The reference points for the measurement of the lengths of the left- and right hands. To determine the hand lengths, the longest line from Tcl on the skin surface of the wrist to the middle fingertip was measured. The arrows indicate the longest points between Tcl and middle fingertip of the right and left hands. 


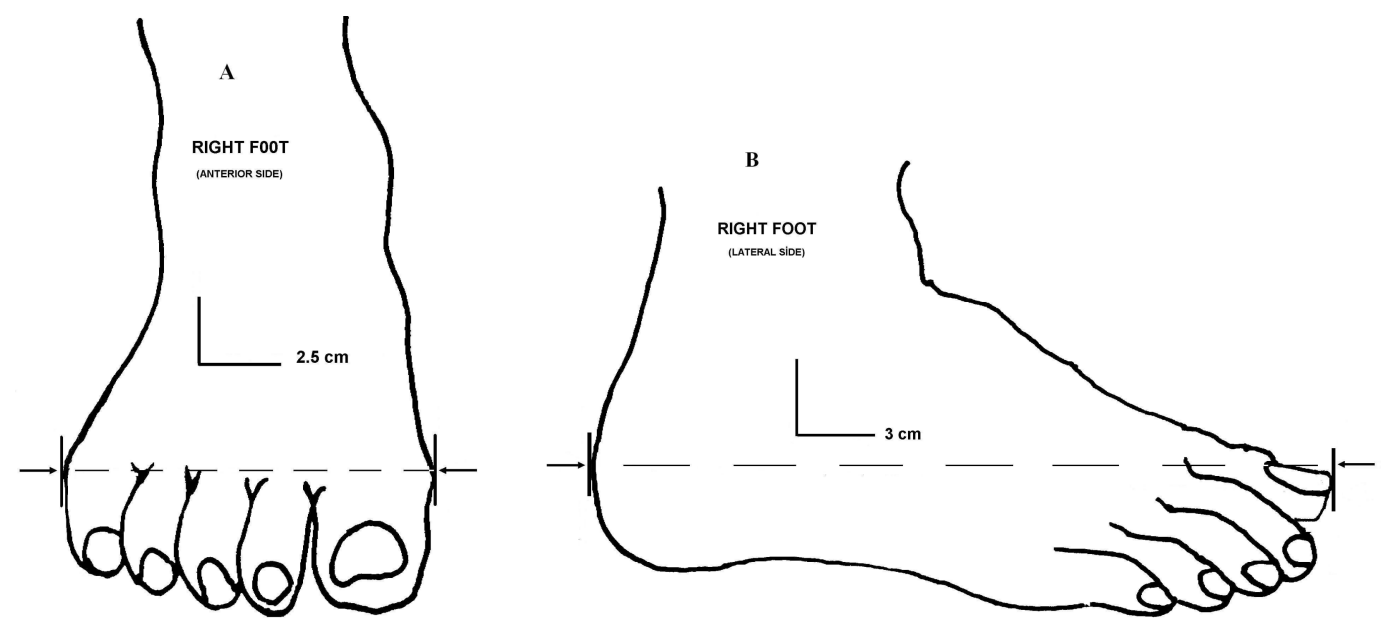

Figure 3. The points of the measurement of foot breadth $(A)$ and foot length (B). The arrows indicate the longest and widest points of right foot. While the line between the first and fifth metatarsals was measured as the breadth of the foot, the length of the foot was measured by taking the distance between the skin surface of the calcanei and fingertip of the thump.

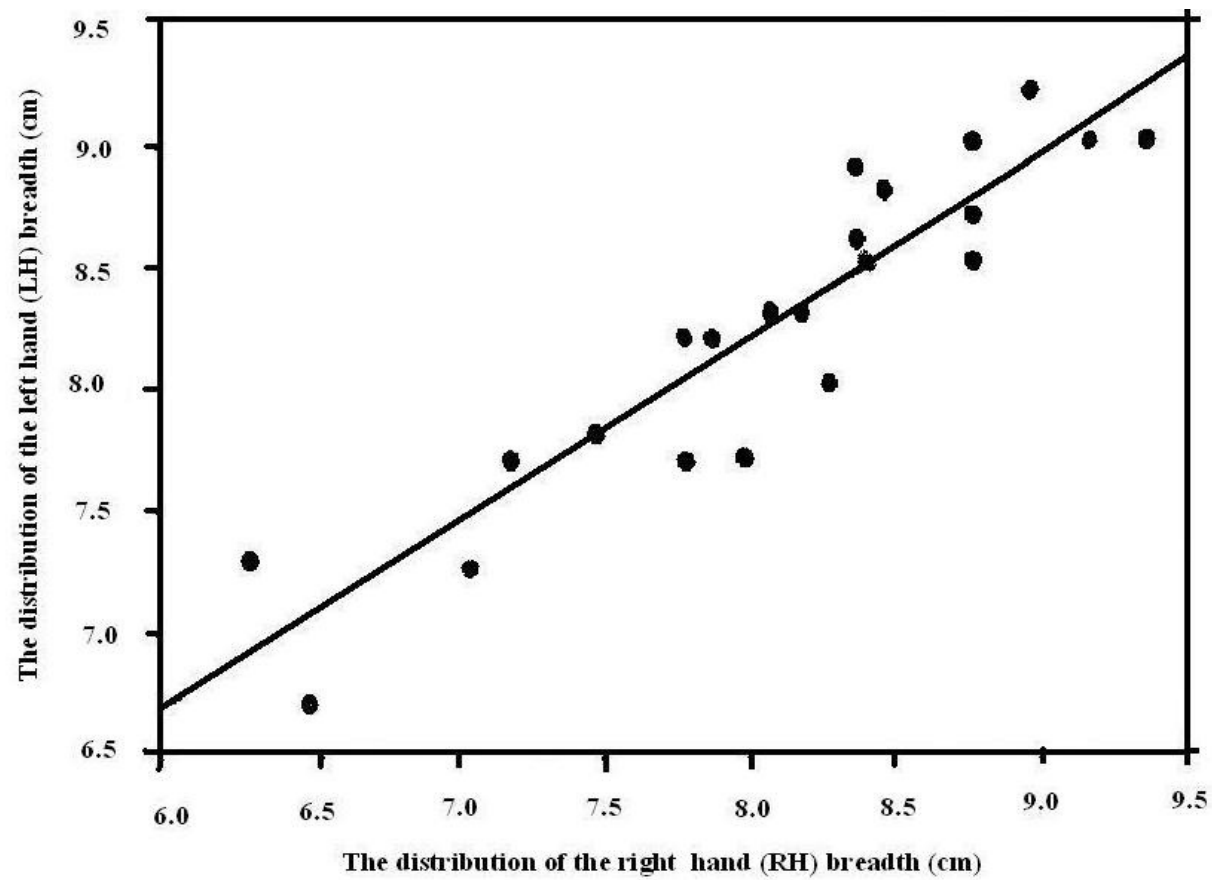

Figure 4. The results of the breadth of the left and right hands observed from left- and righthanders. There is a positive linear correlation between the right and left hand breadth $(\mathrm{cm})$ of the subjects $(n=22, n=221)$ as a morphological features. Statistical results: $t=1.95 ; p<0.05$; $\mathrm{Se}=0.133 ; r=0.921 ; r^{2}=0.8582 ;$ Cor $=0.913$.

task was measured by mechanical and electronic devices (Yetkin, 2002b). The peg-moving performances of the subjects were assessed by a chronometer and recorded (Table 1).

\section{Statistical analysis and descriptive statistics}

The data obtained were summarized as means \pm standard deviation. In the statistical analysis of the results, student's $t$-test, and SPSS for windows 10.0 were used. The data recorded from volunteers were averaged and then analyzed for correlation using the two-sample t-test and ANOVA. The student's test was used to compare male and female subjects, and left and right hand usage. The distribution of GSs for hand preferences was analyzed in percentage. T-test was used to disclose the distribution of hand preferences and hand performances. In addition, the differences 


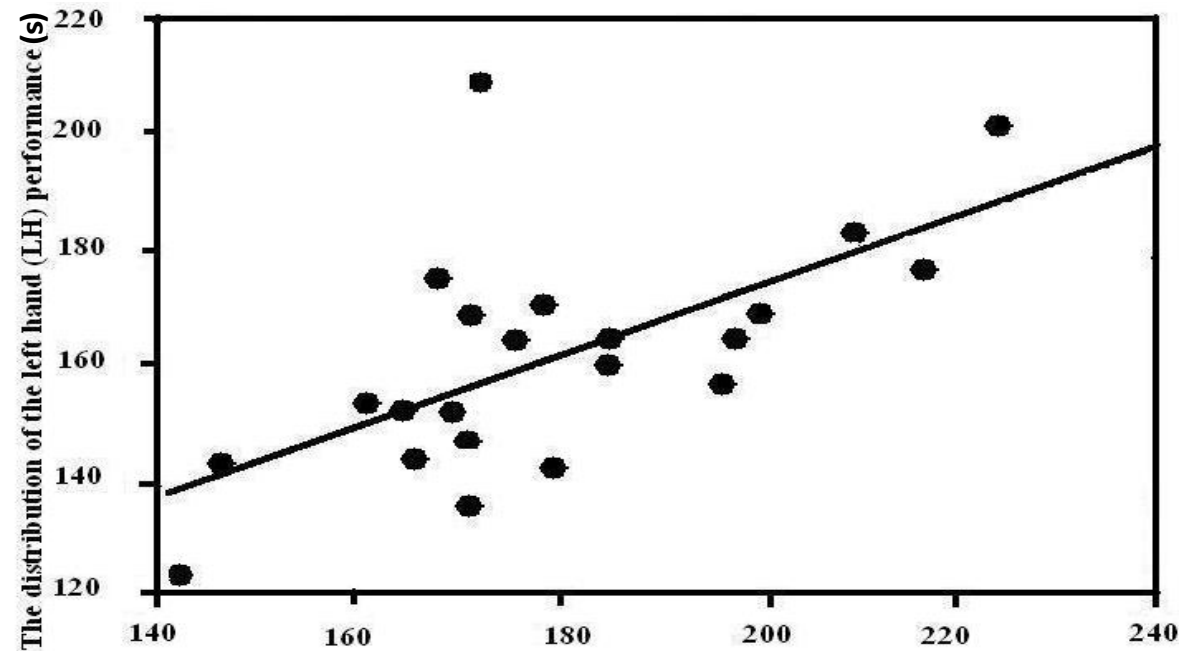

The distribution of the right hand (RH) performance ( $(s)$

Figure 5. The results of the left and right hand performances obtained from peg moving task in left and right-handers. There is a positive linear correlation between the right and left hand performance recorded from peg-moving task (s) (inserting a nail in a hole). Statistical results: $t=-4.74 ; p<0.005 ; S E=4.40 ; r=0.651 ; r^{2}=0.4238$; Cor $=0.630$.

Table 1. Geschwind scores (GSs) of hand preference assessing from Q1 and Q2 points, and Targeting (TT: 100 times), Basketball (BT: 100 times), and Peg Moving Tasks (PMT: 100 nails in a hole -second) performances.

\begin{tabular}{|c|c|c|c|c|c|c|c|c|}
\hline \multirow{2}{*}{$\begin{array}{l}\text { Sexuality } \\
(M \& W)\end{array}$} & \multicolumn{2}{|c|}{$\begin{array}{c}\text { Geschwind score } \\
\text { (GS: \%) }\end{array}$} & \multicolumn{2}{|c|}{$\begin{array}{l}\text { Targeting task } \\
\text { (TT: } 100 \text { times) }\end{array}$} & \multicolumn{2}{|c|}{$\begin{array}{l}\text { Basketing task } \\
\text { (BT: } 100 \text { times) }\end{array}$} & \multicolumn{2}{|c|}{$\begin{array}{l}\text { Peg-moving task } \\
\text { (PMT: sec./100) }\end{array}$} \\
\hline & Q1 & Q2 & $\mathbf{R H}$ & LH & $\mathbf{R H}$ & LH & RH & LH \\
\hline $1 . M$ & 55 & 65 & 100 & 100 & 60 & 30 & 122,60 & 141,60 \\
\hline $2 . W$ & 80 & 65 & 100 & 100 & 0 & 0 & 168,50 & 171,50 \\
\hline $3 . W$ & 40 & 40 & 20 & 40 & 10 & 20 & 142,00 & 180,00 \\
\hline $4 . W$ & 60 & 35 & 40 & 60 & 30 & 40 & 152,00 & 165,00 \\
\hline $5 . W$ & 60 & 60 & 80 & 100 & 30 & 20 & 182,80 & 210,40 \\
\hline $6 . W$ & 55 & 45 & 80 & 60 & 20 & 50 & 202,30 & 224,70 \\
\hline $7 . W$ & 60 & 75 & 100 & 80 & 20 & 20 & 165,00 & 185,20 \\
\hline $8 . M$ & 10 & 60 & 100 & 60 & 30 & 10 & 141,40 & 146,00 \\
\hline $9 . \mathrm{M}$ & 80 & 80 & 60 & 0 & 30 & 30 & 177,30 & 217,30 \\
\hline $10 . \mathrm{M}$ & 40 & 30 & 10 & 80 & 50 & 40 & 152,40 & 169,30 \\
\hline 11.M & 80 & 80 & 20 & 40 & 40 & 20 & 164,30 & 176,00 \\
\hline 12.M & 95 & 70 & 20 & 40 & 40 & 30 & 170,80 & 178,70 \\
\hline 13.M & 85 & 80 & 100 & 100 & 40 & 20 & 135.10 & 170,00 \\
\hline 14.M & 60 & 70 & 100 & 100 & 30 & 40 & 157,00 & 197,00 \\
\hline 15.M & 80 & 40 & 100 & 100 & 60 & 40 & 165,00 & 198,00 \\
\hline 16.M & 75 & 55 & 100 & 100 & 40 & 20 & 143,40 & 165,80 \\
\hline 17.M & 75 & 55 & 100 & 100 & 30 & 50 & 160,00 & 185,00 \\
\hline 18.W & 85 & 80 & 60 & 80 & 30 & 10 & 147,00 & 171,00 \\
\hline 19.M & 85 & 100 & 100 & 100 & 30 & 20 & 168,40 & 200,60 \\
\hline 20.W & 85 & 65 & 100 & 100 & 20 & 10 & 175,00 & 168,00 \\
\hline $21 . W^{*}$ & -55 & -25 & 60 & 80 & 50 & 70 & 210,00 & 172,00 \\
\hline 22.M & 95 & 90 & 100 & 100 & 60 & 70 & 153.20 & 160,80 \\
\hline Arithmetic's means & 63,00 & 60,00 & 79.10 & 78.20 & 34.10 & 30.00 & 161,63 & 179,67 \\
\hline Difference & 3.00 & $\%$ & 0.90 & & 4.10 & & 18.04 & \\
\hline Min. & 10 & 30 & 10 & 0 & 0 & 0 & 122,60 & 141,60 \\
\hline Max. & 95 & 100 & 100 & 100 & 60 & 70 & 210,00 & 217,30 \\
\hline
\end{tabular}

Abbreviations: Q1: the first group of the questions, Q2: the second group of the questions, TT: targeting Task, BT: Basketing task, PMT: peg-moving task, RH: right-hand, LH: left-hand, GS: Geschwind Score, M: men, W: women. 
between Q1 and Q2 group questions related to the left- and right hand preferences during voluntary skills was compared according to GSs. The statistical results are shown in the study's tables and figures.

\section{RESULTS}

The main goals of the present study were to evaluate the relationship between differences of lateralization in the human brain derived from asymmetric function and from voluntary motor tasks involving basketing, targeting and peg-moving tasks.

This study was performed to assess the possible impact of changes in the morphometry of hand and foot sizes arisen by dominant hemisphere and laterality. In the present study, some important results were indicated as related to laterality, especially the relationship between anatomical and functional asymmetry. However, an exploratory study was conducted by Reio et al. (2004). The present work also aims to add to an understanding of hemispheric lateralization by examining the relationships between functional laterality (handedness, eyedness and footedness) and anatomical differences.

The results of the statistical analysis of data showed that most of the subjects tend to use the right hand. The assessment of the hand preferences and the relationship between the two question groups named Q1 and Q2 (Yetkin, 2001) were indicated by GSs. The Q1 by EHI deals only with hand preferences, and the Q2 by YLQ contains the questions related to one side of the body from eye to foot preferences. To assess the relationship between hand, eye and foot preferences, the scores obtained from the first and second group was compared by using t-test. Thus, the hand preferences indicated by Oldfield's (1971) questionnaire and other lateral preferences, such as eye, feet and finger preferences, indicated by Yetkin's questionnaire, were compared.

\section{Analysis of hand preferences}

In order to attain the goal of this study, important results have been obtained by statistical analyses according to the data of the present research. In the small population of 22 subjects, 21 of them were found to be right-handed, corresponding to approximately $95 \%$, while one subject was left-handed, corresponding to $5 \%$. In the larger population ( $n=221), 208$ subjects were right-handed, corresponding to approximately $94 \%$, while 13 of them were left-handed, corresponding to approximately $6 \%$. The percentage of the left-handedness was found to be slightly higher in the second population than in the first population (Table 1).

On the other hand, the mean laterality degrees in righthanders were found to be 63 and $60 \%$ for Q1 and Q2, respectively. For the left-hander who was the only lefthanded person in the population, however, the mean laterality degrees were found to be -55 and $-25 \%$ for Q1 and Q2, respectively.

\section{Morphological asymmetry of the hands and feet}

From the perspective of biomechanical anatomy, the hand is an integral part of the entire arm, and it has a crane-like structure suspended from the neck and upper chest (Wilson, 1998). In the same manner, the foot is an integral part of the entire leg that keeps the body at upright position; it has a carrier-like structure connected to the body by the pelvis and hip joint. The difference between the sizes of the left and right hands and feet were found (Table 2) as discussed thus.

\section{Breadth and length of the hands}

The longest line was measured on the palm from the $2^{\text {nd }}$ to the $5^{\text {th }}$ metacarpi as the breath of the hands (Figure 1). The arrows indicate the widest points of the right and left hands on the palm. The breadth of the hands was measured by compass $( \pm 0.01)$ across inter-metacarpal line.

The thumb was positioned at $45^{\circ}$ apart from the other fingers during the measurement. The difference between the right and left hand breadth was found to be significant $(p<0.05$, Table 3$)$. In the females, the difference between right and left hand breadth ' $d$ ' was also found to be significant $(p<0.05)$ as shown in Table 4.

To determine the hand lengths, the longest line from $\mathrm{Tcl}$ on the skin surface of the wrist to the middle fingertip was measured. The arrows indicate the longest points between $\mathrm{Tcl}$ and middle fingertip of the right and left hands.

The difference between right and left hand lengths was found to be insignificant (Table 3), and there was no difference between the sexes and the left and righthanded subjects ( $p>0.5$; Table 5 ).

Hand breadths and lengths were recorded from the second group with 221 subjects, 208 of which were righthanded and 13 of which were left-handed. In the first group which comprised 22 subjects, 21 of them were right-handed and one of them was left-handed. The statistical result was found in values of $t=1.95 ; p<0.05$; Se $=0.133 ; r=0.921 ; r^{2}=0.8582 ;$ Cor $=0.913$ between left and right breadths. The difference between the right and left hand breadth in females was statistically significant $(p<0.05)$ both in the small $(n=22)$ and large $(n=211)$ groups (Figure 4). However, the difference between the hand widths of the right- and left-handers was found to be insignificant (Table 3). In the same way, the difference between the right- and left-hand lengths was also insignificant in both females and males, and there was no significant relationship between hand lengths of the rightand left-handed subjects, statistically (Tables 4 and 5).

\section{Breath and length of feet}

While the line between the first and fifth metatarsals was measured as the breadth of the foot, the length of the foot was measured by taking the distance between the skin 
Table 2. Hand- breadth $(B)$ and length $(\mathrm{L})$ of the right- $(\mathrm{RH})$ and left-handed $(\mathrm{LH})$ subjects.

\begin{tabular}{cccccc}
\hline \multirow{2}{*}{$\begin{array}{c}\text { Sex } \\
\text { and W) }\end{array}$} & Hand preference & \multicolumn{2}{c}{ Right hand (RH) } & \multicolumn{2}{c}{ Left hand (LH) } \\
\cline { 2 - 6 } 1.M & RH/ LH & RH-B & RH-L & LH-B & LH-L \\
\hline 2.W & RH & 8.70 & 19.40 & 8.80 & 19.30 \\
3.W & $\mathrm{RH}$ & 7.80 & 18.60 & 7.50 & 18.00 \\
$4 . \mathrm{W}$ & $\mathrm{RH}$ & 8.20 & 20.50 & 7.80 & 20.10 \\
$5 . \mathrm{W}$ & $\mathrm{RH}$ & 8.00 & 18.90 & 8.30 & 19.00 \\
$6 . \mathrm{W}$ & $\mathrm{RH}$ & 8.90 & 18.90 & 8.40 & 18.00 \\
$7 . \mathrm{W}$ & $\mathrm{RH}$ & 8.30 & 18.30 & 8.10 & 18.50 \\
$8 . \mathrm{M}$ & $\mathrm{RH}$ & 7.30 & 17.50 & 7.30 & 17.50 \\
$9 . \mathrm{M}$ & $\mathrm{RH}$ & 9.20 & 21.20 & 9.00 & 20.60 \\
$10 . \mathrm{M}$ & $\mathrm{RH}$ & 8.30 & 19.50 & 8.10 & 19.50 \\
$11 . \mathrm{M}$ & $\mathrm{RH}$ & 8.60 & 20.20 & 8.40 & 20.10 \\
$12 . \mathrm{M}$ & $\mathrm{RH}$ & 8.20 & 18.00 & 7.90 & 18.30 \\
$13 . \mathrm{M}$ & $\mathrm{RH}$ & 7.70 & 19.50 & 7.80 & 19.50 \\
$14 . \mathrm{M}$ & $\mathrm{RH}$ & 9.00 & 21.00 & 9.20 & 21.00 \\
$15 . \mathrm{M}$ & $\mathrm{RH}$ & 8.80 & 22.00 & 8.50 & 21.80 \\
$16 . \mathrm{M}$ & $\mathrm{RH}$ & 8.50 & 20.00 & 8.80 & 20.30 \\
$17 . \mathrm{M}$ & $\mathrm{RH}$ & 8.30 & 19.50 & 8.20 & 18.50 \\
$18 . \mathrm{W}$ & $\mathrm{RH}$ & 9.00 & 20.00 & 8.80 & 20.40 \\
$19 . \mathrm{M}$ & $\mathrm{RH}$ & 7.70 & 18.50 & 7.20 & 18.30 \\
$20 . \mathrm{W}$ & $\mathrm{RH}$ & 8.30 & 19.50 & 8.20 & 19.20 \\
$21 . W^{*}$ & $\mathrm{RH}$ & 6.70 & 18.00 & 6.50 & 17.00 \\
$22 . \mathrm{M}$ & $\mathrm{RH}$ & 7.70 & 18.50 & 8.00 & 18.50 \\
Means & $\mathrm{RH}$ & 9.00 & 21.00 & 9.40 & 18.40 \\
\hline & $\mathrm{RH} 1 \mathrm{LH}$ & 8.30 & 18.90 & 8.20 & 18.40 \\
\hline
\end{tabular}

(*) Left handed; B: breadth; L: Length; RH: right hand; LH: Left hand; M: men; W: women.

Table 3. The mean values and results of the data in the total sample by the t-test in SPSS-Windows.

\begin{tabular}{|c|c|c|c|c|c|c|c|c|c|}
\hline Preference & Mean* & Cor. & Sd. & Se. & t-value & df & p-value & $\mathbf{r}$ & $(+,-)$ \\
\hline \multicolumn{10}{|c|}{ Geschwlnd scores (\%) } \\
\hline Q1 & 62.9545 & \multirow{2}{*}{0.801} & 33.369 & 7.114 & \multirow{2}{*}{0.750} & \multirow{2}{*}{21} & \multirow{2}{*}{$>0.463$} & & \multirow{2}{*}{$(-)$} \\
\hline Q2 & 59.7727 & & 26.208 & 5.588 & & & & & \\
\hline \multicolumn{10}{|c|}{ Breadth(cm) } \\
\hline $\mathrm{RH}-\mathrm{B}$ & 8.2818 & \multirow{2}{*}{0.913} & 0.624 & 0.133 & \multirow{2}{*}{1.950} & \multirow{2}{*}{21} & \multirow{2}{*}{$<0.05$} & \multirow{2}{*}{0.921} & \multirow[b]{2}{*}{$(+)$} \\
\hline LH-B & 8.1455 & & 0.179 & 0.166 & & & & & \\
\hline \multicolumn{10}{|l|}{ Length (cm) } \\
\hline $\mathrm{RH}-\mathrm{L}$ & 19.3955 & \multirow{2}{*}{0.939} & 1.289 & 0.275 & \multirow{2}{*}{0.630} & \multirow{2}{*}{21} & \multirow{2}{*}{$>0.538$} & & \multirow{2}{*}{$(-)$} \\
\hline LH-L & 19.3364 & & 1.221 & 0.260 & & & & & \\
\hline \multicolumn{10}{|c|}{ Targeting (100 times) } \\
\hline $\mathrm{RH}-\mathrm{TT}$ & 79.0909 & \multirow{2}{*}{0.743} & 29.906 & 6.356 & \multirow{2}{*}{0.200} & \multirow{2}{*}{21} & \multirow{2}{*}{$>0.840$} & & \multirow{2}{*}{$(-)$} \\
\hline LH-TB & 78.1818 & & 28.223 & 6.017 & & & & & \\
\hline \multicolumn{10}{|c|}{ Basketball (100 times) } \\
\hline $\mathrm{RH}-\mathrm{BT}$ & 34.0909 & \multirow{2}{*}{0.559} & 15.632 & 3.333 & \multirow{2}{*}{1.180} & \multirow{2}{*}{21} & \multirow{2}{*}{$>0.250$} & & \multirow{2}{*}{$(-)$} \\
\hline LH-BT & 30.0000 & & 18.516 & 3.948 & & & & & \\
\hline \multicolumn{10}{|c|}{ Peg moving (100 nails) } \\
\hline $\mathrm{RH}-\mathrm{PMT}$ & 161.6136 & \multirow{2}{*}{0.630} & 20.603 & 4.393 & \multirow{2}{*}{-4.74} & \multirow{2}{*}{21} & & & \\
\hline LH-PMT & 179. 7745 & & 21.550 & 4.510 & & & $<0.005$ & 0.651 & $(+)$ \\
\hline
\end{tabular}

Cor=correlation; $\mathrm{sd}=$ standard deviation; $\mathrm{Se}=$ standard error; $\mathrm{df}=$ degree of freedom; $\left({ }^{*}\right)=$ statistically; $\left({ }^{* *}\right)=(+)$ significant and, (-) in-significant statistically. 
Table 4. The relationship between the right- and left-hand breadths $(B)$ from right- $(\mathrm{RH})$ and lefthanded (LH) men (M) and women (W).

\begin{tabular}{|c|c|c|c|c|c|c|c|}
\hline $\begin{array}{l}\text { Hand } \\
\text { (cm) }\end{array}$ & $\begin{array}{c}\text { Mean } \\
\left(Q 1, Q_{2}\right)\end{array}$ & t-value & p-value & $\begin{array}{l}\text { Sd } \\
\text { (Q1) }\end{array}$ & $\begin{array}{l}\text { Sd } \\
\text { (Q2) }\end{array}$ & df & $(+,-)$ \\
\hline \multicolumn{8}{|c|}{ Total population } \\
\hline $\mathrm{RH}-\mathrm{B}$ & 8.422 & \multirow{2}{*}{1.67} & \multirow{2}{*}{$>.1$} & \multirow{2}{*}{0.70} & \multirow{2}{*}{0.71} & \multirow{2}{*}{420} & \multirow{2}{*}{$(-)$} \\
\hline LH-B & 8.309 & & & & & & \\
\hline \multicolumn{8}{|l|}{ Men } \\
\hline $\mathrm{RH}-\mathrm{B}$ & 8.950 & \multirow{2}{*}{1.47} & \multirow{2}{*}{$>1.4$} & \multirow{2}{*}{0.50} & \multirow{2}{*}{0.50} & \multirow{2}{*}{200} & \multirow{2}{*}{$(-)$} \\
\hline LH-B & 8.845 & & & & & & \\
\hline \multicolumn{8}{|c|}{ Women } \\
\hline $\mathrm{RH}-\mathrm{B}$ & 7. 940 & \multirow{2}{*}{1.96} & \multirow{2}{*}{$<.05$} & \multirow{2}{*}{0.45} & \multirow{2}{*}{0.47} & \multirow{2}{*}{218} & \multirow{2}{*}{$(+)$} \\
\hline LH-B & 7. 817 & & & & & & \\
\hline \multicolumn{8}{|c|}{ Right-handed } \\
\hline $\mathrm{RH}-\mathrm{B}$ & 8.436 & \multirow{2}{*}{1.86} & \multirow{2}{*}{$>.07$} & \multirow{2}{*}{0.68} & \multirow{2}{*}{0.70} & \multirow{2}{*}{396} & \multirow{2}{*}{$(-)$} \\
\hline LH-B & 8.307 & & & & & & \\
\hline \multicolumn{8}{|c|}{ Left-handed } \\
\hline $\mathrm{RH}-\mathrm{B}$ & 8.196 & \multirow{2}{*}{-0.388} & \multirow{2}{*}{$>.7$} & \multirow{2}{*}{0.92} & \multirow{2}{*}{0.82} & \multirow{2}{*}{22} & \multirow{2}{*}{$(-)$} \\
\hline LH-B & 8.333 & & & & & & \\
\hline
\end{tabular}

surface of the calcanei and the fingertip of the thumb. The difference between the left and right foot lengths was also insignificant in the general population, as well as between males and females, and between right- and lefthanded groups (Tables 6 and 7). Foot breadths and lengths were recorded from the second group. The difference between the right- and left-foot widths was found as statistically insignificant $(P>0.05$, Table 6$)$, that is why we have no expected correlation between the data. The differences observed from the general population and between males and females for the left and right foot width were also not significant. Similarly, the differences between the right and left foot lengths were found as statistically insignificant (Table 7).

\section{Functional asymmetry}

By means of the anatomical structure of the hand, we are able to hammer nails or insert nails into a hole or use a pencil; this is an indication of our laterality. The perspective of physiological and functional anatomy suggests that some parts of the brain regulate the hand function.

The problem of understanding what the hand is becomes infinitely more complicated if we try to account for differences in the way people use their hands, or if we try to understand how individuals acquire skill in the use of their hands (Wilson, 1998). The differences between the left- and right hand performances are as given thus.

\section{Targeting (aiming at) performance}

Volunteers in the present study performed the TT a hundred times. However, the action of targeting in previous studies was done for ten times (Yetkin, 1995, 2002b). In this study, there was no significant difference between the right and left performance ( $p>0.8$, Table 1$)$. This result supports our hypothesis on biological evolution of the symmetry. The mean success rate of the targeting performance was approximately 79.10 and $78.20 \%$ for the right and left hand respectively.

\section{Basketing (throwing basketball) performance}

Subjects performed the BT a hundred times. The mean values of the success rate in the BT were 34.10 and $30.00 \%$ for right and left hand performance respectively. The difference between left and right hand preference in the basketball task was not statistically significant ( $p>0.3$ ). However, there are some studies which indicated that the left hand performance is better than the right hand performance in voluntary motor tasks (Tan, 1989; Parlow, 1990). As it is shown in Table 3, the mean success of the BT was lower than the mean success of the TT. 
Table 5. The relationship between the right- and left-hand lengths $(L)$ from right- $(R H)$ and lefthanded (LH) men (M) and women (W).

\begin{tabular}{|c|c|c|c|c|c|c|c|}
\hline $\begin{array}{l}\text { Hand } \\
\text { (cm) }\end{array}$ & $\begin{array}{c}\text { Mean } \\
(\mathbf{Q} 1, \mathrm{Q} 2)\end{array}$ & t-value & $p$-value & $\begin{array}{l}\text { Sd } \\
\text { (Q1) }\end{array}$ & $\begin{array}{c}\text { Sd } \\
\text { (Q2) }\end{array}$ & df & $(+,-)$ \\
\hline \multicolumn{8}{|c|}{ Total population } \\
\hline $\mathrm{RH}-\mathrm{L}$ & 18.066 & \multirow{2}{*}{0.87} & \multirow{2}{*}{$>0.40$} & \multirow{2}{*}{2.415} & \multirow{2}{*}{1.242} & \multirow{2}{*}{420} & \multirow{2}{*}{$(-)$} \\
\hline LH-L & 17.906 & & & & & & \\
\hline \multicolumn{8}{|l|}{ Men } \\
\hline $\mathrm{RH}-\mathrm{L}$ & 19.087 & \multirow{2}{*}{1.11} & \multirow{2}{*}{$>0.27$} & \multirow{2}{*}{3.081} & \multirow{2}{*}{1.055} & \multirow{2}{*}{200} & \multirow{2}{*}{$(-)$} \\
\hline LH-L & 18.727 & & & & & & \\
\hline \multicolumn{8}{|c|}{ Women } \\
\hline RH-L & 17.129 & \multirow{2}{*}{-0.17} & \multirow{2}{*}{$>0.90$} & \multirow{2}{*}{0.820} & \multirow{2}{*}{0.863} & \multirow{2}{*}{218} & \multirow{2}{*}{$(-)$} \\
\hline LH-L & 17.148 & & & & & & \\
\hline \multicolumn{8}{|c|}{ Right-handed } \\
\hline $\mathrm{RH}-\mathrm{L}$ & 18.093 & \multirow{2}{*}{0.906} & \multirow{2}{*}{$>0.37$} & \multirow{2}{*}{2.460} & \multirow{2}{*}{1.232} & \multirow{2}{*}{396} & \multirow{2}{*}{$(-)$} \\
\hline LH-L & 17.917 & & & & & & \\
\hline \multicolumn{8}{|c|}{ Left-handed } \\
\hline $\mathrm{RH}-\mathrm{L}$ & 17.617 & \multirow{2}{*}{-0.135} & \multirow{2}{*}{$>0.90$} & \multirow{2}{*}{1.452} & \multirow{2}{*}{1.428} & \multirow{2}{*}{22} & \multirow{2}{*}{$(-)$} \\
\hline LH-L & 17.696 & & & & & & \\
\hline
\end{tabular}

$\mathrm{Q} 1=$ first ten questions $(\mathrm{EHI}) ; \mathrm{Q} 2=$ second ten questions $(\mathrm{YLQ}) ; \mathrm{B}=$ breadths; $\mathrm{RH}=$ right-handedness; $\mathrm{LH}=$ left-handedness; $\mathrm{M}=$ men; $\mathrm{W}=\mathrm{W}$ omen; $\mathrm{Sd}=$ standard deviation; $\mathrm{df}=$ degree of freedom; $(+,-)^{*}=$ significant (+) and in-significant (-) statistically.

Table 6. The relationship between the right- (RF) and left-foot (LF) breadths (B) from right- and left handed subjects.

\begin{tabular}{|c|c|c|c|c|c|c|c|}
\hline Foot (cm) & $\begin{array}{c}\text { Mean } \\
(\mathbf{Q} 1, \mathbf{Q} 2) \\
\end{array}$ & t-value & $p$-value & $\begin{array}{l}\text { Sd } \\
\text { (Q1) }\end{array}$ & $\begin{array}{c}\mathrm{Sd} \\
(\mathrm{Q} 2)\end{array}$ & df & $(+,-)^{*}$ \\
\hline \multicolumn{8}{|c|}{ Total population } \\
\hline RF-B & 9.607 & \multirow{2}{*}{0.459} & \multirow{2}{*}{$>0.65$} & \multirow{2}{*}{0.965} & \multirow{2}{*}{0.959} & \multirow{2}{*}{420} & \multirow{2}{*}{$(-)$} \\
\hline LF-B & 9.564 & & & & & & \\
\hline \multicolumn{8}{|l|}{ Men } \\
\hline RF-B & 10.285 & \multirow{2}{*}{0.346} & \multirow{2}{*}{$>0.73$} & \multirow{2}{*}{0.810} & \multirow{2}{*}{0.757} & \multirow{2}{*}{200} & \multirow{2}{*}{$(-)$} \\
\hline LF-B & 10.247 & & & & & & \\
\hline \multicolumn{8}{|l|}{ Women } \\
\hline RF-B & 8.984 & \multirow{2}{*}{0.560} & \multirow{2}{*}{$>0.58$} & \multirow{2}{*}{0.613} & \multirow{2}{*}{0.644} & \multirow{2}{*}{218} & \multirow{2}{*}{$(-)$} \\
\hline LF-B & 8.936 & & & & & & \\
\hline \multicolumn{8}{|c|}{ Right-handed } \\
\hline RF-B & 9.626 & \multirow{2}{*}{0.453} & \multirow{2}{*}{$>0.65$} & \multirow{2}{*}{0.970} & \multirow{2}{*}{0.960} & \multirow{2}{*}{396} & \multirow{2}{*}{$(-)$} \\
\hline LF-B & 9.582 & & & & & & \\
\hline \multicolumn{8}{|c|}{ Left-handed } \\
\hline RF-B & 9.300 & \multirow{2}{*}{0.080} & \multirow{2}{*}{$>0.94$} & \multirow{2}{*}{0.858} & \multirow{2}{*}{0.917} & \multirow{2}{*}{22} & \multirow{2}{*}{$(-)$} \\
\hline LF-B & 9.270 & & & & & & \\
\hline
\end{tabular}

$R F=$ right foot; $L F=$ left foot; $B=$ breadth of foot; $\left({ }^{*}\right)$ significant $(+)$, un-significant $(-)$. 
Table 7. The relationship between the right- (RF) and left-foot (LF) lengths (L) obtained from the left- and right handed subjects.

\begin{tabular}{|c|c|c|c|c|c|c|c|}
\hline Foot $(\mathrm{cm})$ & $\begin{array}{c}\text { Mean } \\
(Q 1, Q 2) \\
\end{array}$ & t-value & $p$-value & $\begin{array}{l}\text { Sd } \\
\text { (Q1) }\end{array}$ & $\begin{array}{c}\text { Sd } \\
\text { (Q2) }\end{array}$ & df & $(+,-)^{*}$ \\
\hline \multicolumn{8}{|c|}{ Total population } \\
\hline RF-L & 24.653 & \multirow{2}{*}{0.114} & \multirow{2}{*}{$>0.90$} & 2.10 & \multirow{2}{*}{2.092} & \multirow{2}{*}{420} & \multirow{2}{*}{$(-)$} \\
\hline LF-L & 24.676 & & & 3 & & & \\
\hline \multicolumn{8}{|l|}{ Men } \\
\hline RF-L & 26.183 & \multirow{2}{*}{-0.383} & \multirow{2}{*}{$>0.70$} & 1.67 & \multirow{2}{*}{1.523} & \multirow{2}{*}{200} & \multirow{2}{*}{$(-)$} \\
\hline LF-L & 26.270 & & & 0 & & & \\
\hline \multicolumn{8}{|l|}{ Women } \\
\hline RF-L & 23.248 & \multirow[t]{2}{*}{0.200} & \multirow[t]{2}{*}{$>0.85$} & $\begin{array}{c}1.34 \\
0\end{array}$ & \multirow[t]{2}{*}{1.340} & \multirow[t]{2}{*}{218} & \multirow[t]{2}{*}{$(-)$} \\
\hline LF-L & 23.213 & & & & & & \\
\hline \multicolumn{8}{|c|}{ Right-handed } \\
\hline RF-L & 24.683 & \multirow{2}{*}{-0.131} & \multirow{2}{*}{$>0.90$} & 2.11 & \multirow{2}{*}{2.101} & \multirow{2}{*}{396} & \multirow{2}{*}{$(-)$} \\
\hline LF-L & 24.710 & & & 5 & & & \\
\hline \multicolumn{8}{|c|}{ Left-handed } \\
\hline RF-L & 24.163 & \multirow{2}{*}{0.064} & \multirow{2}{*}{$>0.95$} & 1.89 & \multirow{2}{*}{1.940} & \multirow{2}{*}{22} & \multirow{2}{*}{$(-)$} \\
\hline LF-L & 24.710 & & & 3 & & & \\
\hline
\end{tabular}

Table 8. A comparison between the $Q 1$ and $Q 2$ and functional motor task of right and left handers.

\begin{tabular}{lllcccc}
\hline Parameter & Pair & Mean & $\begin{array}{c}\text { Standard } \\
\text { deviation }\end{array}$ & $\begin{array}{c}\text { Standard } \\
\text { error of mean }\end{array}$ & Min. & Max. \\
\hline Geshwind scores (\%) & Q1 & 62.95 & 33.37 & 7.11 & -55.00 & 95.00 \\
& Q2 & 59.77 & 26.21 & 5.59 & -25.00 & 100.00 \\
Targeting (100 times) & RH-TT & 79.09 & 29.91 & 6.38 & 20.00 & 100.00 \\
& LH-TT & 78.18 & 28.22 & 6.02 & 0.00 & 100.00 \\
Basketing (100times) & RH-BT & 34.09 & 15.63 & 3.33 & 0.00 & 60.00 \\
& LH-BT & 30.00 & 18.52 & 3.95 & 0.00 & 70.00 \\
Peg-moving task (s/100 peg) & RH-PMT & 161.61 & 20.60 & 4.39 & 122.60 & 210.00 \\
& LH-PMT & 179.72 & 21.18 & 4.52 & 141.60 & 224.70 \\
\hline
\end{tabular}

Table 9. Paired comparison for Q1 versus Q2.

\begin{tabular}{lcccccc}
\hline \multirow{2}{*}{ Pair } & \multicolumn{3}{c}{ Paired differences } & \multirow{2}{*}{ t } & df & \multirow{2}{*}{ P value } \\
\cline { 2 - 5 } & Mean & Std. deviation & Std. error mean & & & \\
\hline Q1 - Q2 & 3.18182 & 19.97293 & 4.25824 & 0.747 & 21 & 0.463 \\
\hline
\end{tabular}

Difference between two means is not significant. 
Table 10. Paired comparison for RH-TT versus LH-TT.

\begin{tabular}{lcccccc}
\hline \multirow{2}{*}{ Pair } & \multicolumn{3}{c}{ Paired differences } & \multirow{2}{*}{ t } & \multirow{2}{*}{ df } & \multirow{2}{*}{ P value } \\
\cline { 2 - 6 } & Mean & Std. deviation & Std. error mean & & & \\
\hline RH-TT - LH-TT & 0.90909 & 20.91003 & 4.45803 & 0.204 & 21 & 0.840 \\
\hline
\end{tabular}

Difference between two means is not significant.

Table 11. Paired comparison for basketing task (RH-BT versus LH-BT).

\begin{tabular}{lcccccc}
\hline \multirow{2}{*}{ Pair } & \multicolumn{3}{c}{ Paired differences } & \multirow{2}{*}{ t } & \multirow{2}{*}{ df } & \multirow{2}{*}{ P value } \\
\cline { 2 - 5 } & Mean & Std. deviation & Std. error mean & & & \\
\hline RH-BT - LH-BT & 4.09091 & 16.23022 & 3.46029 & 1.182 & 21 & 0.250 \\
\hline
\end{tabular}

Difference between two means is not significant.

Table 12. Paired comparison for RH-PMT versus LH-PMT.

\begin{tabular}{lcccccc}
\hline \multirow{2}{*}{ Pair } & \multicolumn{3}{c}{ Paired differences } & \multirow{2}{*}{ t } & \multirow{2}{*}{ df } & \multirow{2}{*}{ P value } \\
\cline { 2 - 5 } & Mean & Std. deviation & Std. error mean & & & \\
\hline RH-PMT - LH-PMT & -18.10909 & 17.91958 & 3.82047 & -4.740 & 21 & 0.000 \\
\hline
\end{tabular}

Difference between two means is significant $(P<0.001)$.

\section{Peg-moving (Sarah-peg works) performance}

In PMT, performance of the right hand was found to be better than that of the left hand. The mean values were 161.6136 and $179.7745 \mathrm{~s}$ for the right and left hand, respectively. The difference was about $18 \mathrm{~s}$. The difference between the right and left hand performance was significant $(\mathrm{t}=-4.74 ; \mathrm{p}<0.005 ; \mathrm{SE}=4.40 ; \mathrm{r}=0.651$; $r^{2}=0.4238$; Cor $=0.630$ ). The results are shown in Table 3 and Figure 5.

\section{Comparison between the Q1 and Q2 and the functional motor task of a right and left hander: The results of the descriptive statistics}

Descriptive statistics of Geshwind scores and functional motor task of the right and left handed subjects were assessed separately (Table 8 to 12). According to the laterality, the mean Geshwind scores were found as 62.95 and $59.77 \%$ for Q1 and Q2 respectively. The difference between Q1 and Q2 was about $3.18 \%$ mathematically. The targeting (100 times) task for RH-TT (79.09 times) and LH-TT (78.18 times) were rather close to each other.

There was no significant difference, mathematically. Basketing (100 times) task was found for RH-BT (34.0 times) and LH-BT (30.00 times). The mean difference was found to be $4 \%$. However, the difference in the pegmoving task (s/100 pegs) was RH-PMT (161.61) and LHPMT (179.72) separately.

According to the paired comparison for $\mathrm{Q} 1$ versus $\mathrm{Q}$, the difference between the two means (3.18\%) was not significant $(p>0.05)$. The paired comparison for $\mathrm{RH}-\mathrm{BT}$ versus LH-BT of basketing task was found to be 4.09091, and the difference between the two means was not significant $(p>0.05)$. According to the paired comparison for RH-PMT versus LH-PMT, the difference $(-18.10909)$ between the two means was significant $(P<0.001)$. Also, a paired comparison was done for $\mathrm{RH}$-TT versus LH-TT, and the difference (0.90909) between the two means was not significant $(p>0.05)$.

\section{DISCUSSION}

In the present study, firstly, the constructional, biomechanical and functional characteristics of the hands and feet were investigated after which a comparison was made for them. This study presents the application and observational data that suggest possible effect of functional asymmetries on morphological and anatomical differences of the hands and feet. In humans, handedness is thought to be related to the hemispheric processing of specific aspects of language, including speech (Redmond and Lamperez, 2004). The development of the lateralized functions have also been assessed as being important to cognitive, emotional, perceptual, social, and motor skills (Young, 1983).

A number of studies have recently been carried out in animals as it was in humans; paw preferences (Tan et al., 1991; Tan, 1993b; Yetkin, 2001) and physical properties in cats are closely related to the measurements of hand 
and foot sizes in human. There is a harmonic relation between the use of the hand and brain functions as evolutionary phenomena (Niebauer et al., 2004). In the anthropologic process, the brain develops a device and the hand is used to make it. Then, the brain is used to make more developing devices. Thus, a harmonic relation was set between the hand and the brain. Presumably, people may have heard that the two distinct hemispheres of the brain have different capabilities. For example, the sensory control from the left side of the body is sent to the right hemisphere of the brain, and the sensory control from the right side of the body is sent to the left hemisphere of the brain. Likewise, the control of the right arm and leg is sent to the left hemisphere, and the control of the left arm and leg is sent to the right hemisphere. The left hemisphere is said to deal with language and analytical thought, while the right hemisphere is said to deal with spatial relations and creativity (Kimura, 1996).

Broca (1861) showed that asymmetry was a hallmark, and that symmetry increased as asymmetry went down the phylogenetic scale in biological evolution (Yetkin, 2002a). In the light of this opinion, the female's brain is more symmetrical than that of the male, and children show more symmetry than adults (Finger, 1994). Appropriate differences in motor functions between the left and right hemispheres have always been discussed to find a structural correlation for the functional asymmetry. An anatomical difference between hemispheres was identified about four decades ago (Geschwind, 1965; Geschwind and Levitsky, 1968). The superior aspect of the temporal lobe known as the planum temporale was significantly found to be larger on the left than on the right side (David and Hugdal, 1995, Westbury et al., 1999; Williams, 2001).

The hypothesis stipulates that one of the organs, which are symmetric in biologic systems, can develop more than the other ones, if it works much more than the other ones (Darwin, 1871).

The purpose of this work is to develop a method of using a maximal forced laterality maneuver for the study of morphologic and functional asymmetry induced by hand usage. For this goal, the results and findings were discussed in the light of anthropological and evolutionary, biomechanical and physiological, and neurobehavioral and developmental perspectives (Wilson, 1998). To our knowledge, this work is the first study that is conducted to examine the relationship between hand preferences and hand and foot sizes. The relationship between the functional asymmetry and the sizes of the body parts such as hand, foot and brain would be an evidence for the reason of the morphological asymmetry. However, the reason for the asymmetry is still not a completely clarified concept. Hence, the main purpose of this study is to determine the morphological asymmetry of the hands and feet as preferences. The hand plays an important role in daily life (Napier, 1956). There is a close relationship between the function of the brain and the preference of the hand and foot (Glick and Shapiro, 1985; Previc 1991; Yetkin, 1993). It is known that this is a result of the fact that psycho-motor setting up of one hand is more effective than that of the other. A hand preferred for a particular action can be superior to the other in the realization of that action.

A considerable amount of articles is already available on the hand preference (Annett, 1970a; Oldfield, 1971; Phillips, 1986; Knecht et al., 2000), and the functional and morphological asymmetry (Yetkin, 1992) observed in common daily activities of human kind. However, new research areas have recently emerged on the laterality of the voluntary motor skills, such as targeting, basketball and peg moving task (Tan, 1992; Yetkin, 1995), and hand and foot sizes related to the functional asymmetry. These preferences and handedness are generated by the central nervous system (CNS) (Hammond, 1990). The present paper has concentrated upon the questions of which hand, foot and eye do humans use to perform their daily activities (Annett, 1972; Yetkin, 1993), how many papers have been published on the plasticity of the functional and morphological asymmetry (Annett and Kilshaw, 1983; Kilshaw and Annett, 1983; Lewis, 1989; Tan, 1989, 1994a; Tan and Kutlu, 1992) and how many of them affect conduction velocity related to hand usage in humans' daily activities. Humans are able to learn a remarkable array of skilled motor tasks and perform them with such proficiency that movements become almost automatic (Lisberger, 1988).

Anthropologic studies (Tattersall, 1998) show graphic representation of the hand which has been found on the walls of the cave of Pech Menle (Kapandji, 1981; Jordan, 1999). After humans were able to walk in an upright position on hind extremities, they began to use the hands freely in daily activities. Thus, the anatomical and functional asymmetry of the hands emerged depending on the hand used. Moreover, there is a principle in biology; if one of the symmetric organs in an organism would be used in daily activities more than the other one (Annett, 1981), it can be denser than the other (Yetkin, 1993). Our findings also support the morphological asymmetry between left and right hands as related to their lateral performance.

The hand is also a sensory organ by way of manufacturing and carrying more specialized tools (Annett, 1970b; Marzke, 1997). For this, the body and hand complement each other. On the other hand, according to Immanuel Kant, the hand is also outside of the human brain: humans can interact with the world and make tools to easy their life (Young, 1983).

\section{Morphological asymmetry}

Study of the embryology of the hand is of utmost interest on the studies of the hand. It helps in understanding a lot 
of unexpected aspects of the anatomy of the hand. The hand sizes begin to assume adult features at 13 to 14 years of age. The phalangeal epiphyses become wider than the shaft. The carpal bone attains their mature size. At the age of 16 to 18 years, all phalange epiphyses unite with the shafts. The radial epiphysis reaches its mature size and unites with the shaft. The ulnar epiphysis also unites with the shaft (Tubiana, 1981a). The hand lies flat on a smooth area and the pronated forearm lies in a posterior-anterior way. The hand is stretched out with the thumb held wide apart, and the vertical beam is classically countered below the midpoint of the interstyloid line. For special examination of the hands (or fingers), the beam was focused more distally on the head of the third metacarpal (Tubiana, 1981b). Foot preferences are also considered as an evidence for anatomical and functional asymmetry. In some behaviors, however, motor functions seem to be similar in the dominant and non-dominant leg in apparently healthy young adult men and women (McCurdy and Langford, 2005).

In the present study, the difference between the right and left hand breadth was found to be statistically significant $(p<0.05)$ for both the first small group $(n=22)$ and the second large $(n=211)$ group (Figure 4) in females. However, the difference between the right and left hand breadth was found to be statistically insignificant $(p>0.1)$ in males. The difference of the right and left hand lengths was also found to be statistically insignificant in both males and females. Similarly, there were insignificant relationships between the hand lengths of right and left-handed males and females.

The differences between the right and left foot breadth and lengths were found to be insignificant in males and females and right and left handed subjects. Hand and foot measurements are not common practices in radiology except in trauma or congenital defect of the hands and foots. Several comprehensive studies have been made at different ages on hand sizes in both sexes.

There is a difference between the brain of men and women as to which part of the left hemisphere is responsible for speech and hand movements. There are two major areas devoted to speech, one in the frontal lobe, and the other at the back, where the temporal and parietal lobes meet. In women, the frontal region is more important than the area at the back; so, problems with speaking are more likely to happen if the front part of the left hemisphere is damaged. In men, the areas contribute more equally, but if anything, the back part, especially the parietal region, is more important (Kimura, 1996).

\section{Functional asymmetry}

The hand is characterized greatly with prehensile capabilities, such as pincer-like movements, wrappingaround, the use of gravity in conjunction with placement of the hand in hook-like position and the use of palmar plateau for grasping (Tubiana, 1981), and different free flexor movement of the fingers. One of the aims of the present study was to investigate the effect of hand preference on morphological and anatomical differences. In this study, discussions on some motor tasks are further given (Winter, 1990). The results are discussed in terms of implications for voluntary tasks about differences in left- and right-handed persons. A similar study was made on the drawing performance of the children (Vlachos and Bonoti, 2004; Long, 1981).

\section{Targeting (aiming at) performance}

The differences between the left and right hand performance observed in voluntary motor tasks, including basketball (mean performance of $3.9 \%$ ) and targeting (mean performance of $90 \%$ ), were found to be statistically non-significant ( $p>0.05)$. These results can also be described as biological phenomena. If the hands can be used freely without depending on a tool, it seems to be that the degree of laterality for hand preferences goes toward symmetry. In addition, one side of the body is used together with a hand for motor tasks. As it is known, brain hemispheres control both sides of the body reciprocally. It shows that there is a close affinity between the brain hemispheres functionally. The results of a study conducted by Simon-Thomas et al. (2005) suggest that emotional responses facilitated the right hemisphere processing during higher cognitive task performance. However, the left hemisphere controls the motor performance. This means that motor performance is more effective on morphological asymmetry than on cognitive performance.

With targeting and basketball performances, despite the fact that objects looked larger in the right eye of righteye dominant subjects and in the left eye of left-eye dominant subjects (McManus and Tomlinson, 2004), an investigation has also been performed on the lateral side of the body from eye to foot. On the other hand, there were few studies on 'aiming at' in adults in the preferred and non-preferred hands in right handed adults (Barral and Debu, 2004). The results obtained from targeting in this study support those results. Volunteers conducted the performance of TT a hundred times. In some previous studies, however, the action of targeting was provided for ten times (Yetkin, 1995, 2002b). In this work, there was no remarkable difference (about 1 point) between right and left performance, and this difference was also nonsignificant $(p>0.8$; Table 1). This result supports our hypothesis which stipulates that symmetry is a biological process related to evolution.

The mean success of the targeting performance was approximately 79.10 and $78.20 \%$ for right and left hand respectively. However, the mean targeting performance was found to be higher $(78.65 \%)$ than basketball performance $(32.05 \%)$, but the difference between the 
left and right hand performance was statistically insignificant. In these actions, subjects experienced their right and left hand separately for a hundred times to perform the targeting and basketball tasks.

The subjects used their index finger together with the left and right eye during targeting. The index finger can assume the various degrees of skills needed for adjusted movement levels without involving other fingers (Oldfield, 1971; Kilbreath and Gandavia, 1994; Yetkin, 1995).

\section{Basketing (throwing basketball) performance}

Subjects conducted the basketball task a hundred times. The mean values were 34.10 and $30.00 \%$ for right and left hand performance, respectively. The difference between left and right hand performance for basketball was 4 point, which was non-significant $(p>0.3)$. However, there are some studies which indicate that the performance of the left hand is better than that of the right hand for voluntary motor tasks (Tan, 1989; Parlow, 1990). As shown in Table 3, the mean success of the BT was lower than that of the TT.

\section{Peg-moving task / Sarah-peg work performance}

There are different studies on the peg-moving task (Suguieda et al., 2008) and there are different pegboards for this task. A new peg-board developed by Yetkin was used in this study which has a hundred holes, whereas the peg-board used in previous studies that were conducted recently had 25 holes (Tan and Kutlu, 1992). The time required for the PMT on the board with 25 holes was too short for the exact difference to emerge between the right and left hand performance, although, the subjects might spend too much time for the difference between the right and left hand performance to emerge on a board with hundred holes.

In PMT, the mean of the right hand performance was found to be better than that of the left hand performance. The performance was 161.61 and $179.78 \mathrm{~s}$ for the right and left hand, respectively, and a difference of $18 \mathrm{~s}$ was significant $(\mathrm{t}=-4.74 ; \mathrm{p}<0.005 ; \mathrm{r}=0.651)$. The results are shown in Table 3, and the linear correlation between leftright hand performances for PMT is shown in Figure 5. The difference between right- and left- hand for PMT was about $18 \mathrm{~s}$. This is a big difference. It shows that the right hand which was used for PMT was more conducive than the left hand.

\section{Sex differences}

When the results obtained from men and women were compared, the relation between them was found to be statistically significant. Although the main purpose of the present study was not to compare the differences between the sexes, this characteristic was appraised in this report.
Finally, if the studies related to functional and morphological asymmetry are based on biological principles depending on the brain functions, the mechanisms of both symmetry and asymmetry can be better understood. Biological principles of physiological functions, such as motor skills, learning, memory, motor and mental developments (Eccless, 1989) in human beings can be discussed on the right basis.

\section{Conclusions}

In conclusion, it was found that there was a significant relation $(p<0.05)$ between right and left hand breaths in women (Table 4). The mean breath of the right hand was larger than that of the left hand in all subjects (Table 3). This is a wonderful sample for anatomical asymmetry. These results show that there is an anatomical asymmetry between the left and right hand widths, which could depend on their usage. Similarly, there was a significant difference between the left and right hand performance for PMT that could be related to hand preference. This is also a wonderful sample of functional asymmetry depending on hand performance. These findings support our opinion on laterality and its reason during the evolutionary process (Parsons et al., 1998; Corballis et al., 2000). Results of this study explain the effects of the morphological and anatomical differences of functional asymmetries of the brain hemispheres. These findings also support our opinion related to the evolution of symmetry as a biological phenomenon.

\section{REFERENCES}

Adams RD, Victor M, Ropper AH (1997). Principles of Neurology, 6th edition. McGraw-Hill Inc, New York. pp. 275-350.

Annett M (1970a). The growth of manual preference and speed. Br. J. Psychol. 61:545-558.

Annett M (1970b). A classification of hand preference by association analysis. Br. J. Psychol., 61: 303-321.

Annett M (1972). The distribution of manual asymmetry. Br. J. Psychol. 63:343-358.

Annett M (1981). The right-shift theory of handedness and developmental language problems. Bull. Orton Soc. 31:103-121.

Annett M, Kilshaw D (1983). Right and left hand skill II. Right and left hand skills- II. Estimating the parameters of distribution of $L-R$ differences in males and females. Br. J. Psychol. 74:269-83.

Annett M (1985). Left, Right, Hand and Brain: right shift theory. Lawrence Erlbaum Associates Ltd., London.

Annett M (1996). In defense of the right shift theory. Perceptual Motor Skill 82:115-137.

Bakan P (1975). Are left- hander brain damaged? Neuroscientists 67:2000-2002.

Barral J, Debû B (2004). Aiming in adults: Sex and laterality effects. Laterality 9(3):299-312.

Broca P (1861). Portée de la parole:Ramolisement Chronique et Destruction Partielle du Lobe Anterieur Gauche du Cerveau. Paris Bull. Soc. Anthropol. pp. 2-4.

Cohn MJ (2002). Giving limbs a hand. Nature 406:953-54.

Corballis PM, Funnell MG, Gazzaniga MS (2000). An evolutionary perspective on hemispheric asymmetries. Brain Cognit. 43:112-117.

Corballis MC (2009). The evolution and genetics of cerebral asymmetry. 
Philosophical Transactions of the Royal Society B: Biol. Sci. 364(1519):867-87.

Coren S (1992). The left-hander Syndrome. The course and consequences of left- handedness. Free Press, New York.

Davidson R, Hugdahl K (1995). Brain Asymmetry. In: R Davidson and K. Hugdahl (Eds.), The Asymmetrical Brain. MIT Press, Cambridge, Massachusetts.

Eccles J (1989). Evolution of the Brain. Routledge, New York.

Finger S (1994). Origins of Neuroscience: A History of Explorations into Brain Functions. Oxford University Press Inc., New York.

Geshwind N (1965). Disconnection syndromes in animals and man, Part I and II. Brain 88:237-294.

Geshwind N (1967). Wernicke's contribution to the study of aphasia. Cortex 3:449-450.

Geschwind N (1971). Aphasia. N. Engl. J. Med. 284:654-656.

Geshwind N, Galaburda A (1984). Cerebral Dominance: The Biological Foundation. Harvard University Press, Cambridge, Massachusetts.

Geshwind N, Galaburda A (1987). Cerebral lateralization: Biological Mechanisms, Association and Pathology. MIT Press, Cambridge.

Geshwind N, Levitsky W (1968). Human brain: Left-right asymmetries in temporal speech region. Sci. 161:186-187.

Glick SD, Shapiro RM (1985). Cerebral Lateralization in Nonhuman Species. New York: Academic Press.

Hammond GE (1990). Cerebral Control of Speech and Limb Movements. The University of Western Australia, Nedlands, Australia.

Hellige OB (1990). Hemispheric asymmetry. Psychology 41:51-80.

Jordan P (1999). Neanderthal: Neanderthal man and the Story of Human Origins. Sutton Publishing, New York.

Kapandji IA (1981). The Hand, Part III. In: R Tubiana (ed.), The hand in art. WB Saunders, Philadelphia. Chapter 64, pp. 715-722

Kilbreath S, Gandavia S (1994). Limited Independent Flexion of the Thumb and Fingers in Human Subjects. Br. J. Physiol. 3:484-97.

Kilshaw D, Annett M (1983). Right and left hand skill I. Effect of age, sex and hand preference showing superior skill in left-handers. Br. J. Psychol. 74:25-68.

Kimura D (1993). Neuromotor mechanisms in human communication. Oxford University Press, New York.

Kimura D (1996). Understanding the Human Brain In: Cox J (Ed.), Children's Britannica. Encyclopedia Britannica Inc., London. pp. 136141.

Kimura D (2001). From ear to brain. Brain Cogn. 76(2):214-7.

Knecht S, Dröger B, Deppe M, Bobe L, Lohmann H, Flöel A, Ringelstein $E B$, Henningseen $H$ (2000). Handedness and hemispheric language dominance in healthy humans. Brain 123:2512-18.

Kupfermann I (1999). Localization of Higher Cognitive and Affective Functions. The Association Cortices. In: Kandel ER, Schwartz JH (Eds.) Jessell TM, Principle of Neural Science. Elsevier, New York. pp. 515-38.

Leroi-Gourhan A (1988). Hand and Worth (La geste at la parole): Die Evolution von Technik, Sprache und Kunst. Suhrkamp Taschenbuhch, Germany. pp. 42-80.

Lewis OJ (1989). Functional Morphology of the Evolving Hand and Foot. Clarendon Press, Oxford.

Lisberger SG (1988). The neural basis for motor learning in the vestibule-ocular reflex in Monkeys. Trends Neurosci. 11(4):147-148.

Long C (1981). Electromyographic Studies of Hand Function. In: Tubiana R (ed.), The Hand; Part III, VI. W. B. Saunders, Philadelphia. Chapter 64.

Marzke M (1997). Precision Grips, Hand Morphology and Tools. Am. J. Phys. Anthropol. 102:91-110.

McCurdy K, Langford G (2005). Comparison of unilateral squat strength between the dominant and non-dominant leg in men and women. $J$ Sports Sci. Med. 4:153 - 159

McManus IC, Tomlinson J (2004). Objects look different sizes in the right and left eyes. Laterality 9(3):245-265.

Mohr JP (1976). Broca's area and Broca's aphasia. In: Whitaker HA and Whitaker H (eds.), Studies in Neurolinguistic. MIT Press, New York. pp. 201-235.

Napier J (1956). The prehensile Movements of the Human Hand. J. Bone Joint Surg. 4:902-13.

Niebauer CL, Christman SD, Reid SA, Garvey KJ (2004).
Interhemisfepheric interaction and beliefs on our origin: degree of handedness predicts beliefs in Creationism versus evolution. Laterality 9(4):433 - 447.

Oldfield RC (1971). The Assessment and Analysis of Handedness: The Edinburgh Inventory. Neurophysiology 9:97-113.

Parsons LM, Gabrieli JDE, Phelps EA, Gazzaniga MS (1998). Cerebrally lateralized mental representations of hand shape and movement. J. Neurosci. 18:6539-6548.

Phillips C (1986). Movements of the hand. Liverpool University Press, Liverpool England.

Previc HF (1991). A general theory concerning the prenatal origins of cerebral lateralization in human. Psychol. Rev. 98:298-334.

Purves D, Augustine GJ, Fitzpatrick D, Katz C, LaMantia AS, McNamara JO, Williams SM (2001). Neuroscience: Language and Lateralization, 2nd edition. Sinauer Associates, Sunderland, Massachusetts. Chapter 27.

Purves D, Augustine G, Fitzpatric D, Katz LC, La MAS, McNamara JO, Redmond JC, Lamperez A (2004). Leading limb preference during brachiation in the gibbon family member, Hylobates syndactylus (siamangs): A study of the effects of singing on lateralization. Laterality 9(4):382-396.

Reeves RH (2000). Recounting a genetic story. Nature 405: 283-284.

Reio TG, Czarnolewski M, Eliot J (2004). Handedness and spatial ability: Differential patterns of relationships. Laterality 9(3):339-358.

Rothwell J (1994). Control of Human Voluntary Movement. Chapman and Hall, New York.

Simon-Thomas ER, Role KO, Knight RT (2005). Behavioral and Electrophysiological Evidence of a Right Hemisphere Bias for the Influence of Negative Emotion on Higher Cognition. J. Cognit. Neurosci. 17(3):518-529.

Sperry RW (1974). Lateral specialization in the surgically separated hemispheres. In: Schmidt FO and Worden FG (eds.), Neuroscience; 3rd Study Program. MIT Press, Cambridge, Massachusetts. pp. 5-19.

Steenhuis R, Bryden MP (1989). Different Dimensions of Hand Preference that relate to Skilled and Unskilled Activities. Cortex 25:289304.

Suguieda DY, Nunes G, de Oliveira SB, Dellatolas G, da Paz AC, Braga LW (2008). Computerized procedure for analyzing hand kinematics with a peg-moving task (Sarah-Pegworks). Behav. Res. Methods 40(2):503-11.

Tan $U$ (1988). The distribution of hand preference in normal men and women. Int. J. Neurosci. 41:35-55.

Tan U (1989). Manual proficiency in Cattle's intelligence test in lefthanded male and female subjects. Int. J. Neurosci. 44:17-26.

Tan Ü, Kara I, Kutlu N (1991). The effect of the testosterone on paw preference in adult cats. Int. J. Neurosci. 56:187-191.

Tan U, Kutlu N (1992). Right and left hand skill in relation to cerebral lateralization in right handed male subjects: The prominent role of the right brain in the right handedness. Int. J. Neurosci. 64:125-138.

Tan U (1993a). Normal distribution of hand preference and its bimodality. Int. J. Neurosci. 68:61-65.

Tan U (1993b). Distribution of paw preference in mongrel and tortoiseshell cats and the relation of hemispheric weight to paw preference: Sexual dimorphism in paw use and its relation to hemispheric weight. Int. J. Neurosci. 70:199-212.

Tattersall I (1995). The Fossil Trail: How We Know What We Think We know about Human Evolution. Oxford University Press, New York.

Tattersall I (1998). Becoming Human: Evolution and Human Uniqueness. Hardcourt Brace and Co., New York.

Tubiana R (1981). Architecture and Functions of the Hand. In: Tubiana $R$ (ed.), The Hand I. WB Saunders, and Philadelphia.

Tubiana R (1981). The Hand I. WB Saunders, Philadelphia. pp. 493498

Vlachos F, Bonoti $F$ (2004). Left- and right-handed children's drawing performance: Is there any difference? Laterality 9(4):397- 409.

Vogan KJ, Tabin CJ (1999). A new spin on handedness asymmetry. Nature 397:295-298.

Wada JA, Clarke R, Hamm A (1975). Cerebral hemispheric asymmetry in humans: cortical speech zones in 100 adult and 100 infant brains. Arch. Neurology 32:239-246.

Wernicke K (1874). Der Aphasische Symptomkomplex. Braslau, Kohn and Weigert. In: English Translation by GH Eggert Wernicke's Works 
on Aphasia, A Source Book and Review (1977). The Hague, Moulon. Westbury CF, Zatorre RJ, Evans AC (1999). Quantifying variability in planum temporale: A probability map. Cerebral cortex 9:392-405.

Wiesendanger M, Nirkko A (2001). Hand und Hirn: Forschung-Lehre. Publication DPG 16:7-13.

Williams SM (2001). Language and Lateralization. In: Purves D, Augustine GJ, Fitzpatrick D, Katz LC, LaMantia AS, McNamara JO, Williams SM (eds.), Neuroscience, 2nd edition. Sinauer Associates, Sunderland, Massachusetts.

Wilson FR (1998). The Hand. Pantheon Books, New York. pp. 56-127.

Winter DA (1990). Biomechanics and motor control of human movement (2nd Ed.). Wiley \& Sons, New York.

Yetkin $Y$ (1993). The examination of preferences related to using of right or left hand, foot and eye. Trends J. Med. Sci. 19:133-142.

Yetkin $Y(1995)$. Laterality during voluntary tasks of young males and females. Trends J. Med. Sci. 23:129-134.
Yetkin Y (2001). Do environmental and hereditary factors affect the psychophysiology and Left-right shift in left-handers? Int. J. Neurosci. 110:109-34.

Yetkin $Y(2002 a)$. Physical properties of the cerebral hemispheres and paw preferences in Mongrel cats: sex-related differences. Int. J. Neurosci. 112:239-262.

Yetkin Y (2002b). A comparison related to the laterality of the voluntary motor performance such as basketing, targeting and peg-moving. Anadolu Univ. J. Sci. Technol. 3:31-40.

Young G (1983). Manual Specialization and the Developing Brain. Academic press, New York. 